International Journal of Linguistics, Literature and Translation

ISSN: 2617-0299 (Online); ISSN: 2708-0099 (Print)

DOI: $10.32996 / \mathrm{ijllt}$

Journal Homepage: www.al-kindipublisher.com/index.php/ijllt

\title{
Analysis of Foreign Learners' Lexical Errors: A Case Study of Kassala University
}

\author{
Dr. Suad Abdelwahid Fadlallah 8 (D) \\ Assistant Professor, Department of English Language and Linguistics, College of Education, University of Kassala, Sudan \\ Corresponding Author: Dr. Suad Abdelwahid Fadl Allah, E-mail: suadfadlallah@yahoo.com
}

\begin{tabular}{|c|c|}
\hline ARTICLE INFORMATION & ABSTRACT \\
\hline Received: May 12, 2021 & The aim of this paper is to identify the types of lexical errors made by learners in Sudan \\
\hline Accepted: June 25, 2021 & in producing English words. To achieve these purposes, the researcher offered three \\
\hline $\begin{array}{l}\text { Volume: } 4 \\
\text { Issue: } 6\end{array}$ & $\begin{array}{l}\text { questions. The data was gathered from free compositions writing test. The study } \\
\text { sample consists of } 50 \text { students enrolled in the Department of Enqlish lanquage at }\end{array}$ \\
\hline DOI: $10.32996 /$ ijllt.2021.4.6.20 & $\begin{array}{l}\text { Kassala University. To answer the study questions, the frequency tables and percent } \\
\text { were used. The findings of the study indicate that the students committed errors }\end{array}$ \\
\hline KEYWORDS & resulting from mother tongue interference and other factors such as \\
\hline $\begin{array}{l}\text { Error analysis, Lexical Errors, } \\
\text { Interference, Overgeneralization }\end{array}$ & $\begin{array}{l}\text { overgeneralization and incomplete application of rules. Recommendations are } \\
\text { suggested that lexical errors still need more studies and investigation because it is a } \\
\text { very wide area and very difficult one. }\end{array}$ \\
\hline
\end{tabular}

\section{Introduction}

Error Analysis (EA) is a linguistic activity that aims at systematically describing errors made by learners of a foreign language. It goes beyond this to give us insights into the psycholinguistic process of language learning since learners produce some of their "intake".

The importance of vocabulary in second language writing is widely accepted, but there has been relatively little research into several lexical errors learners produce when writing in their second language. Empirical evidence suggests that lexical errors are the most frequently occurring. Inappropriate lexical choices will lead to misunderstanding of the message directly or at least to an increase in the burden of interpreting the text. It is an indisputable fact that the teacher plays a crucial role in the learning /teaching process. Sullivan (2001: 66-86) believes that foreign language teachers are fundamentally different from other teachers in that they are attempting to teach a second language using that very language as the medium of instruction. Since" the medium is the message," unique challenges arise for English language teachers and learners.

\subsection{Aims of the study}

This study aims to identify the types of lexical errors made by English language students in Sudan. More specifically, the study attempts to answer the following questions:

1. What are the most common types of lexical errors made by English language students?

2. What are the possible causes of these errors?

3. What are the implications of the findings for teaching English in Sudan?

\subsection{Scope of the Study}

The subjects chosen to conduct this study were the fourth-year English language students enrolled in the Department of English language at Kasala University. They were 50 students (males and females) and their age ranged from 20-23years.

\subsection{Statement of the Problem}

Lexis is one of the major problems that confront EFL learners and due to their 'anemic vocabulary, they are unable to communicate their ideas as clearly as they would like to.

\section{K C AL-KINDI CENTER \\ $R$ DFR RESEARCH AND}

Your gateway to world-class research

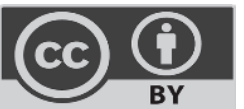

Published by Al-Kindi Center for Research and Development, London, United Kingdom. Copyright (c) the author(s). This open access article is distributed under a Creative Commons Attribution (CC-BY) 4.0 license 
The researcher found EFL students' selection of words when writing is improperly and inaccurately selected. Also, they are unable to grasp the ideas transmitted to them. Research on lexical errors made by second/foreign language student writers is scarce in comparison to research in other problematic areas in writing, such as grammar.

\subsection{Method and Procedures}

The students in English Department have studied EEL courses for ten years: three of the basic school, three at secondary school and four at university; they speak Arabic as their mother tongue. That level of the students was chosen because they are available and easy to contact.

The material of this research is originally free compositions writing test for 50 students of the fourth year. A free composition writing test was found as a suitable technique to elicit the data needed for this study in comparison with other techniques as translations or others. This is because it allows one to see how language learners apply their learned vocabulary or words which they have taught in their language texts. The compositions were written in class for 3 hours under examinations conditions. The students were asked to write about 1-1.5 pages on the following topics:

1- The contribution of women to the National Economy

2- The role of parents in the family

3- Kasala City

Since the present study has different objectives for the identification of errors, the following steps were followed:

1- The compositions were carefully marked

2- The lexical errors were underlined

3- The errors were classified into main categories: spelling errors, inflexion errors, transfer, and shortage of vocabulary, collocation, phrasal verbs and synonyms. The researcher made sub-classes, e.g. within the inflection errors, noun errors, verbs errors, adjective errors, and adverb errors. Also, within the shortage of vocabulary, sub-classes were made as using Arabic vocabulary and using long erroneous sentences.

4- A frequency count of errors was made and the results were tabulated.

5- The table reveals the number and percentage of the errors made in the compositions.

To comment on each type of error, the following steps were followed 1-Erroneous sentences from the data were cited as examples:

1-Corrections were made, but the errors which needed explanation remained with put correction so that each sentence contained only one error.

2-The right form of the sentence is written between two parentheses tinder the wrong sentence.

3- In the case of mother tongue interference, the Arabic counterparts of the wrong English sentences were produced in the phonetic transcription

\section{Literature Review}

\subsection{Lexis}

Lexis has been sharply differentiated from grammar. Grammar is said to be organized in 'closed" systems, to be systematic and regular. Leech (1981:179): grammar is "that part of language which can be described in terms of generalizcttions or rules".

While lexis appertains to:

"All the particular facts about language those which cannot be generalized into rules"

Lexis is, by contrast, said to consist of "open" systems, to be irregular and unsystematic. For Sinclair (1987) lexis involves "the vagaries of individual words".

\subsection{What does it Mean to Know a Word}

Writers as McCarthy (1990), Taylor (1983) and Medani (1994) have discussed many ideas and notions under this title, which seems to be clear for the learner for the first time, but it involves different ideas and points of view.

The answer for this question is not as easy as it seems.

Medani (1994:39) stated that: knowing a word is knowing the lexical information (aspects) that is related to it, and involves questions of whether the information about a particular lexical item, is available for both comprehension and production or whether it is only available for comprehension. 
Knowing a word according to Richards (1976) in James (1997:) suggested that there are seven things to know about a word:

(i) Its morphology. Knowledge of a word's spelling and pronunciation would be included here also.

(ii) Its syntactic behavior: not to say explain me this.

(iii) Its functional or situational restrictions: not to say (electrical) __ tension but current.

(iv) Its semantic value(s) or denotations: not to say I broke my foot for the intended leg.

(v) Its secondary meanings or connotations: not to say, (gang of policemen) when you mean (squared or contingent), since (gang) is associated with trouble makers.

(vi) What other words, it is associated with: that (sofa) belongs to the semantic field of "furniture" and associates with (bed, stool etc.)

(vii) Roughly how likely the word is to be used, that is, its frequency.

Shaughnessy (1977:190) quoted from James (1997:146). She stated: when we say that a student does not know a word, we do not generally mean he has never heard or seen it.... But errors in the vocabulary already attest to the student's knowledge, at some level, of the words he is using or (miss using)".

\subsection{Meaning}

The meaning of the word "meaning' has many popular uses; meaning within the semantic and lexicography has been given more than one definition.

Leech (1974:10) used this word to mean "all that is communicated by language ".

Different writers used different terms to refer to meaning. For example, Lyons (1977) used the term 'sense" whereas Leech (ibid) used "conceptual meaning", both referring to cognitive meaning. Antony (1957) defined the term meaning as follows:

"It is a slice of the non-language world used as a reference and connected to lexical world.

When I say that the word 'pitch" means a number of different things: the statement is a short hand for saying that the word 'pitch" is bonded to a group referents".

According to Leech, the difference is that Antony ties meaning with the real world, while conceptual meaning is related to cognition rather than referring to the real world. In other words, it refers to the contrastive defining features which distinguish concepts in the language from one another. For example, according to Leech (1974), the word woman could be defined as (+ human, - male, + adult) as distinct from the boy who could be defined as (+ human, male, - adult).

Semantic field theory asserts that lexical meaning cannot be fully understood by looking at a word in isolation but by looking at a group of semantically related words. Semantic relations can refer to any relationship in meaning between lexemes, including polysemy (the different meaning associated with a word), synonymy (big and large), antonymy (big and small), and hyponymy (rose and flower).

\subsection{Polysemy}

It is another important paradigmatic relationship. Part of the definition of the word (rider) in the Longman Dictionary of Contemporary English is as follows:

1- a person who rides or is riding, especially a horse.

2- a statement, opinion, or piece of advice, especially to an official declaration or verdict.

Among the problems facing lexicographers is whether a word like (rider) is one form with several meanings (polysemy) or whether that there are severed words, having the same form (homonymy) from the viewpoint of the learner, a load of learning is the same no matter whether the word is polysemous or homonymous. It simply involves assigning different meanings to a single form:

The problem in learning English polysemous words for the first language learners can be shown in the following examples quoted from Hamad (1995:20).

A simple lexical item in the $\quad=$ more than one simple 1 complex

Target language

e.g. uncle

A polysemoues target

item in the first language

$=\mathrm{khál} / \mathrm{am}$

$=$ more than one word in

Language word

e.g. right

the first language, each word being the equivalent of each sense

= Sahih (correct)/ yamin (the opposite of left).

The above example says the learners have one target language, which he/she has to treat as polysemous (having the sense of both the first language equivalents). According to (Hamad), the word uncle is a polysemous word since there is a separate word 
for the brother of a father and another for the mother's brother. Also, the last example above contains a real polysemic word for each sense of which there is a number of first language equivalents.

\subsection{Synonymy}

Palmer (1976:88) states that "synonymy" is used to mean sameness of meaning. The two forms are closely related in meaning but the idea of "sameness of meaning", used in discussing synonymy, is not necessary "total sameness".

The learners' ability to differentiate between synonymy rather than his ability to spot common attributes is important, which deserves mentioning. This is true since learners regard synonyms as complete synonyms. The learners know that the words are related, but they do not know that they differ from each other. The learners who use $L_{1}$ (first language) in their learning, such as using bilingual dictionary only, will translate such word into one word in their first language and the result is that these words will be treated as complete synonyms. Consider the following example quoted from Hamad (1995:19).

$$
\text { E.g. /yashuf/ = look /see/watch. }
$$

The above example is a case of divergence and the equivalents are synonyms.

Another good example when you have a simple lexical item in the first language which may come to have more than one simple I complex item in the target language, and the target language equivalent are not necessary synonyms:

$$
\text { e.g. / sá a/ = watch / clock }
$$

\subsection{Collocations}

Many difficulties face students with the new vocabulary items. These difficulties may be choosing the correct combination of two or more words because words for the foreign learners do not co-occur freely and there are many restrictions.

Collocations refer to the lexical environment in which a word can occur. The collocates of a word are the words with which it can co-occur. Consider the following example quoted from Yule:

The hamburger ate the man.

The man ate the hamburger.

The above example, according to Yule (1985), is semantically odd although syntactically correct. The sentence here is erroneous because of the infringement and violation of proper collocation of some words. If we asked why the sentence is odd? The answer may relate to the component of conceptual meaning of the noun hamburger, which differs significantly from those of the noun man when those nouns are used as subjects of the verb ate.

Errors of this kind reflect the lack of collocational competence in the learner and they are bound to make errors in using a system they have not completely mastered.

Richards., (1976:70) states that the knowledge

of collocation 'means that on encountering

such as fruit" we can expect the words ripe, green..."

Lyons (1977) noticed that in connection with the lexemes drink when coining across a sentence such as he drank $\mathrm{x}$, the native speaker would suppose that this $x$ must-have feature (+ liquid) because this is what the lexeme drink selects, not what it prefers. An interesting comparative study of some collocations in English and French is Whitaker, (1992) in James, (1997:153). A comparison is made of the distributions of the verb pairs come / go and aller / venire, with the purpose of explaining why French learners of EL2 make errors in selecting come and / or go despite having a similar contrast in the LI. The reason is that students tend to assume there is a one-to-one correspondence, a belief sometimes encouraged by teaching. This was proved false by getting high proficiency French-English bilinguals to translate high-frequency uses of come / go into French. Nation (2001) asserts that collocational knowledge is significant in enhancing fluency: "all fluent and appropriate language use requires collocational knowledge".

\subsection{Research on Lexical errors}

TL research in the 1970s and early 1980 has recently been under strong criticism for the paucity of research on lexical learning. Abdallah Abu Naba'h (2011) showed two main categories of errors: interlingual and Intralingual errors. Interlingual errors accounted for $85 \%$ and intralingual errors accounted for $15 \%$ of the total errors. Interlingual errors respectively take the form of translation, assumed synonymity, wrong collocation motivated by L1, confusion of binary terms, and overuse of some lexical terms. On the other hand, intralingual errors were due to phonic and graphic resemblance and overgeneralization.

Nadia A. Shalaby, Noorchaya Yahya and Mohamed El-Komi (2009) found that the underlying source for most lexical errors in their study can be traced back to L1 influence, though some may be caused at the same time by minimal or incomplete knowledge of 
the English diction. With this in mind, they suggest that teachers use lexical error taxonomies or develop their own in their vocabulary teaching. We strongly believe that these taxonomies not only serve as research tools but, more importantly, as instructional tools that teachers should employ.

Using a very limited taxonomy, Akande, Adedeji, and Okanlawon (2006) stated that their 225 students' lexical errors fit under only three categories: overgeneralization of rules, wrong analogy and wrong spelling. In their study, they investigated the lexical errors of 225 final year technical college students. A 20-item fill-in multiple-choice test and an essay writing exercise were administered to the students. The researchers found that technical college students did not have high competence in the use of words related to their different areas of specialization as they normally made mistakes resulting from overgeneralization of rules, wrong analogy and wrong spelling. They suggested that English teachers in Nigerian technical colleges should tailor their teaching of English to reflect the lexical needs of their students. By failing to provide a comprehensive, detailed taxonomy, however, the study collapses the many different types of

errors under a few headings and therefore overlooks many specific types of sources of lexical errors.

Hemchua and Schmitt (2006) present a taxonomy that incorporates a wide range of lexical error categories. Their proposed taxonomy can account for lexical errors more specifically than the typologies presented in other research studies.

Llach ( 2005: 16) said that a lexical error is the wrong word use of a lexical item in a particular context in comparison with what a native speaker of similar characteristics as the L2 learner (age, educational level, professional and social status) would have produced in the same circumstances. Lexical errors can also be defined as a breach in a lexical norm of the language, which native speakers normally observe.

The area of lexical errors has not been widely investigated before.

Mahmoud (2005) presented a systematic analysis of Arab EFL learners' lexical errors in general and of collocation errors in particular. His study presents empirical data verifying the informal observations and theoretical assertions that EFL learners produce 'unnatural' word combinations. A total of 420 collocations were found in 42 essays written by Arabic-speaking university students majoring in English. About two-thirds of these collocations (64\%) were incorrect, and 80\% were lexical collocations instead of grammatical ones. He found that $61 \%$ of the incorrect combinations were due to negative transfer from Arabic. Mahmoud, however, focused his work on only one type of lexical errors, collocations.

Abisamra (2003) also analyzed errors in ten essays written by ten Lebanese students in grade nine. The subjects use English as the language of instruction since nursery and have been taught English by Americans and Canadian teachers. The results show that the total number of errors that were detected in the ten essays was 214 . The number of intralingual errors was 137 (64.1\%), while the number of interlingual errors was 77 (35.9\%).

Wang (2003) maintained that switching between first (L1) and second (L2) languages had been recognized as one of the salient characteristics of $\mathrm{L} 2$ writing. However, it is not clear how switching between languages is related to $\mathrm{L} 2$ proficiency or how switching to the L1 assists writers with differing L2 proficiency in their composing.

Szymanka (2002) discusses lexical problems areas in the language of advanced Polish speakers of English. She presented two data samples drawn from PELCRA learner corpus, representing two groups of students at different proficiency levels. The results show that collocation errors are among the most widely represented error categories in both groups. She suggested that the theory of the bilingual lexicon has to incorporate the collocation restrictions among L1 and L2 lexical items to a larger extent than it has been proposed so far.

Hamad Alseed (1995) investigated the lexical errors of the second-year English students of the faculty of Arts, University of Khartoum. He also made use of materials that were obtained from the students' composition. He concluded that of the types of lexical information that he investigated, spelling errors turned out to be associated with the highest percentage (3 7-40 \%). He attributed learners' spelling problems to two reasons: the English system and the students' ignorance of language rules.

Although disputable, it has been attributed to the neglect by Target language (TL) researchers and pure linguistics Hatch (1978), Levenston (1979) Meara (1980-1984).

Krashen (1981:109) made the point that the teaching profession restricts vocabulary in order to focus on syntax.

Meara (1984) criticized the limitations of the data collection techniques and data treatment, which is the analysis of learners' errors.

Latterly, lexis has been begun to take a central role in language study.

In addition to what has been mentioned above concerning the previous studies relevant to the topic under research, one can say that there are some Sudanese studies carried out by post-graduate students, and students of 5-year honour degree (Khartoum 
University and Ahfad University). Obviously, these studies are in the areas of Error Analysis, for example, tenses errors, Articles errors and the areas that might cause problems for Sudanese learners. Besides, some Sudanese and other studies investigated the lexical errors in the written production.

\section{Discussion}

Six hundred sixty-five deviant lexical errors were identified and classified according to their possible source of errors. It is important to mention that quantification of errors does not include frequencies of individual lexical items and the types of errors are by no means exclusive. In many cases, they are overlapping. It is also necessary to mention that native English speakers may easily understand some sentences, yet they obviously deviate from academic writing.

To answer the first and the second questions of the study, "what are the most common types of lexical errors made by English language teachers?" and "what are the causes of these errors?" the responses of the subjects were corrected and lexical errors were identified and recorded.

The following is a discussion of each classification type of errors that may be suggested.

\section{Spelling Errors}

Spelling is important for everybody to communicate his ideas and it is an important factor in writing.

In this study, 30 compositions written by 50 students were chosen and investigated for spelling errors. To achieve this, the same procedure as that described in chapter three are followed.

Some errors are resulting from the nature of the English language itself. Words that have the same pronunciation

(homophones),e.g. peace and piece, hole and whole, have always been a source of spelling errors.

Examples from the data:

$$
<\text { called }>_{,}<\text {cold }>
$$

1-There is a tribe which is cold hadandwa.

(There is a tribe which is called hadandwa).

Some letters which are pronounced similarly caused misspelling: $<\mathrm{c}>$ is sometimes pronounced as / $\mathrm{k} / \ldots \rightarrow$ : cook, describe. Examples:

2- My mother kooks the food.

(My mother cooks the food).

3- Kasala is deskribed as a beautiful town.

(Kasala is described as a beautiful town)

$$
<\text { nice }>\text {, <nise }>
$$

4- Kasala is a nise city

(Kasala is a nice city)

The / $\mathrm{p} /$ and / $\mathrm{b} /$ are two different phonemes with different pronunciations and spelling, but, still some students tend to misuse them.

$<$ contribution> < contripution>

5- The contripution of woman to the National Economy.

(The contribution of woman to National Economy)

$<$ describe $><$ descripe $>$

6-If I want to descripe the city

(if I want to describe the city)

The plural of noun is usually made by adding's' to the singular.

Example: house, houses

However nouns endings ' $y$ ' proceeded by a consonant form their plural by changing the ' $y$ ' into ' $i$ ' and adding 'es' thus:

Example: city, cities

$$
\text { -y - - - ites }
$$

Some students overgeneralize this rule and produce the following spelling error:

Kasala is one of the biggest citys

(Kasala is one of the biggest cities)

Spelling errors like parants, togethar, maney in the following examples

7-The role of parants in the family

(The role of parents in the family)

8- Father and mother work togethar.

(Father and mother work together) 
9- The father who earns maney

(The father who earns money)

These are due to a lack of experience with spelling. While spelling errors like weman, suitable in the following examples:

10- The contribution of weman in.

(The contribution of woman in....)

11- The suitible job for women.

(The suitable job for woman)

These could be attributed to the un-phonetic nature of English spelling, where one vowel sound is represented by many letters. Spelling errors constitute (32.5) of the lexical errors investigated in this study, which is shown in table (1). To sum up, we can say spelling errors were attributed to overgeneralization due to the nature and irregularity of English spelling in addition to the inadequate and lack of exposure to written texts. The teaching methods used by teachers encourage carelessness among students.

\section{Inflection Errors}

They are classified under the following categories

\section{Nouns}

Some nouns are caused by the learner's application of the English rules that he/she has learned. The learner borrows an element from one part of the structure of English and forces it into another. This is why he/she produces the wrong plural forms of closed-class nouns. The plural of a noun is usually formed by adding " $s$ " to the singular, e.g.

Boy boys home homes

A few nouns form their plural by vocalic change as:

Woman women, foot feet

The plural morpheme $/ \mathrm{s}$ / is sometimes added to the singular of an irregular noun as in the following examples:

12- Womans are very important members of society.

(Women are very important members of society)

13- Heaven is under mother's foots.

(Heaven is under mother's feet)

Difficulties arise in the case of collective nouns. Mass or collective nouns have one form, e.g. behaviour, people; they are always in the singular.

However, students make them plural by adding the plural morpheme "s" and treat them as such, e.g.

14-There are many peoples in kasala.

(There are many people in kasala)

15-. Like their parent's behaviors.

(......................ike their parent's behavior)

Some nouns in English have two different forms, one for the singular and another for the plural. Some students, because of ignorance or confusion of rules, mistakenly add the plural " $s$ " to the singular form of the noun to form its plural such as: Example:

16- Mothers prepared their childs for the future,

(Mothers prepared their children for the future)

Noun errors constitute (22.4\%) of the inflection errors investigated in this study shown in table (1).

\section{Verbs}

The general rule of adding "-ed" to form the past tense and adding "-en" to form the past participle are often applied to irregular verbs such as:

(cut cut, come came, leave left)

Students made errors by adding "-ed" to the past tense of irregular verbs as in the following examples:

17- The farmer selled fruit.

(The farmer sold fruit)

18- When you leaved the town.

(When you left the town)

The irregular verbs of English are one of the difficulties facing the learners due to their inconsistency. The difficulties lie in the fact that the irregular verbs in English have got to be memorized; otherwise, they cannot be used correctly. Thus, the students made errors in the use of irregular verbs because of their ignorance of the rules of the conjugations of these verbs. 
When the students fail to produce the right form, they try to extend its use by over-generalizing the general rule ("-ed" addition to the base form) of English regular to irregular ones as well. This claim is supported by Selinker, (1974:70) who says that:

"............ the past tense morpheme -ed is extended to an environment which, to the learner, it could logically apply,

but just does not".

The carelessness of the students is evident in the following example:

19- They broked the rule.

(They broke the rule)

Because after he / she used the right past tense of "break" which is "broke", he / she wrongly added the "-ed" to the past tense. Verbs errors constitute (50.9\%) of the inflection errors investigated in this study.

\section{Adjectives}

An adjective is a word used to modify a noun (e.g. green gardens, new city) when forming the comparative and superlative. Some students tend to generalize the rule of forming them by adding "-er" and "-est" to all adjectives indiscriminately.

Examples from the data:

20- The role of the mother is very great than

(The role of the mother is greater than)

More than one syllable adjectives form the comparative by using "more than" and superlative by using "the most" with the positive form of the adjective: example:

21- Kasala is the beautifulest city in Sudan.

(Kasala is the most beautiful city in Sudan)

22- There is no person kinder than the mother.

(There is no person more kind than the mother)

The above errors could be attributed to the irregularity of the formation of comparatives and superlatives in the Target Language (TL) on the one hand and the inadequate teaching of English on the other hand.

Adjectives errors constituted (21. 1\%) of the inflection errors investigated in this study as shown in table (1).

\section{Adverbs}

The adverb is said to modify a verb, an adjective or other adverb.

Most adverbs of manner (describe the way in which an action occurs, e.g. carefully, badly) are formed by adding "-ly" to the corresponding adjectives.

Some adjectives which end in "ly" have no adverb forms. To supply this deficiency, a similar adverb or adverb phrase is used, such as:

Friendly (adjective), in a friendly way (adverb phrase). Students identify such adjectives as adverbs and use them as such in the following example:

23- Father is a kindly man.

(Father is a kind man).

Adverbs errors constituted (5.6\%) of the inflection errors investigated in this study as shown in table (1).

Errors under the category of inflection constitute (24.2\%) of the lexical errors investigated in their compositions. They are classified into:

noun (22.4\%), verbs (50.9\%), adjectives (21.1\%) and adverbs (5.6\%) showed in the following table:

Table (1): Distribution of Inflection Errors

\begin{tabular}{|c|c|c|}
\hline Type of errors & Number of errors & Percentages \\
\hline Nouns & 36 & $22.4 \%$ \\
\hline Verbs & 82 & $50.9 \%$ \\
\hline Adjectives & 34 & $21.1 \%$ \\
\hline Adverbs & 9 & $5.6 \%$ \\
\hline Total & 161 & $100 \%$ \\
\hline
\end{tabular}

\section{Transfer}

The foreign learners transfer the grammatical system, the pronunciation and the vocabulary of their native language into the target language. The learner does this unconsciously by transferring the habit system of his native language to the TL. Examples from the data;

24- The farmer prepared the land.

(The farmer cultivated the land) 
25- Parents climax of good behavior

(Parents must be a model of good behavior)

The learner here used "climax" for "model" which he means in Arabic/ gima fi al?khlag/.

Due to interference of Arabic, the learner reversed the order of the adjective and noun, e.g.

26- To be family good.

(To be good family)

27- The top of the hills are covered with ice.

(The top of the hills are covered with snow)

Errors under this category (17.4\%) of the lexical errors investigated in this study.

\section{Shortage of Vocabulary}

Errors under this category have shown an occurrence of the total number of lexical errors in the data. They are class.

\section{Using Arabic Words}

When the learner has difficulty finding the target language $(T L)$ lexical item that may convey the intended meaning, they resort to the translation of the equivalent item from their mother tongue (MT) and use it in the target context.

Example:

27- All people in kasala like drinking jabana.

(All people in kasala like drinking coffee)

28- You find very beautiful and green swagi.

(You find very beautiful and green gardens)

Using Arabic words constituted (10\%) of the shortage of vocabulary observed in the data.

\section{Using Long Erroneous Sentences}

Here, a learner normally gives a description of the intended lexical item where he fails to produce the proper lexical item to use in a certain context, as in the following example from the data:

29- In kasala there is a garden of animals.

(In kasala there is a zoo)

30- The tribes have their special talks.

(The tribes have their own languages)

The learner in example (29) above is short of vocabulary and in order to convey the meaning he paraphrases the word "zoo".

Using long erroneous sentences constitute (90\%) of the shortage of vocabulary observed in those compositions.

Errors under the category of shortage of vocabulary constitute

(105\%) of the lexical errors investigated by the study. They are classified

into: using Arabic vocabulary (10\%) and using long erroneous sentences

$(90 \%)$ as seen in the following table.

Table (2): Distribution of Shortage of Vocabulary Errors

\begin{tabular}{|l|c|c|}
\hline Type of errors & Number & Percentage \\
\hline Using Arabic words & 7 & $10 \%$ \\
\hline Using long erroneous sentences & 63 & $90 \%$ \\
\hline Total & 70 & $100 \%$ \\
\hline
\end{tabular}

\section{Collocation}

Collocations are words that normally keeps company with other words (James,1998:152). It is also a habitual association between particular words. The learner must know which words typically precede and follow this word.

Examples from the data:

31- Their answer the question.

(Their answer to the question)

32- The father makes a try.

(The father makes an attempt)

In the above example (32) "an attempt" is preferred despite the synonymy of attempt/try. They have different ranges of application. In example (31) the word answer is always followed by "to", the learner unable to collocate such words in English.

33- The farmer has suffered big loses 
(The farmer has suffered heavy loses)

The difficulties illustrated by the sentences above include problems of co-occurrence-, the learners were not aware of the certain restriction on the permitted combination of words.

Errors of this kind I think are due to the nature of English.

Collocation errors constitute (14.3\%) of the lexical errors investigated in this study.

\section{Phrasal Verbs}

In Arabic, there is no item comparable to the phrasal verbs in English. For example, there is no item in Arabic equivalent to the difference between "find" and "find out".

Example from the data:

34- Fathers always try to find the causes of the quarrelling.

(Fathers always try to find out the causes of the quarrelling)

The Arabic word for "find" is/ yajid / which could be correct in the above example, although there is also an equivalent to "find out" / yaktashif /, the particle is omitted thus to "find out" / yaijid / to English.

the following

Also students sometimes misuse some phrasal verbs because they are not able to differentiate between their uses as in example:

35- The mother looks about her children

(The mother looks after her children)

Errors under this category constituted (.6\%) of the lexical errors observed in this study.

\section{Synonyms}

English is said to be very rich in synonyms because of the French, Latin and Greek influences on the language. Since no two lexical items in any two languages cover exactly the same meaning areas, it is important to learn lexical items in context. There is no complete one-for-one correspondence between the words of one language and those of another. Example from the dam:

36-If the mother is ill.

(If the mother is sick)

The learner here misuses "ill" for "sick"

37-There are many causes for doing that.

(There are many reasons for doing that)

In the above example, the students tend to be confused as to which English word they have to use.

Synonyms errors constitute (5\%) of the lexical errors investigated in this study.

The following table would reveal the number and percentage of lexical errors investigated in this study.

Table (3): Distribution of Lexical Errors

\begin{tabular}{|l|c|c|}
\hline Type of errors & Number & Percentage \\
\hline Spelling errors & 216 & $32.5 \%$ \\
\hline Inflection errors & 161 & $24.2 \%$ \\
\hline Transfer & 116 & $17.4 \%$ \\
\hline shortage of vocabu1ary & 70 & $10.5 \%$ \\
\hline Collocation & 95 & $14.3 \%$ \\
\hline Phrasal verbs & 4 & $.6 \%$ \\
\hline Synonyms & 3 & $.5 \%$ \\
\hline Total & 665 & $100 \%$ \\
\hline
\end{tabular}

The students were seen to commit errors resulting from mother tongue interference and other factors such as overgeneralization and incomplete application of rules of the target language.

4.

Findings

The general picture of the students' errors resulting from the investigation showed that there is still a lot of weakness in the different levels of language analysis. The English knowledge of the $4^{\text {th }}$ year English language students in words is very weak. Students written compositions reflect an inadequate grasp of Lexis properties, i.e. spelling, collocation, inflection etc. which eventually reduced the overall lexical knowledge. The investigation showed that spelling is a major area of difficulty for the fourth English language students. Spelling errors constituted (32.5\%) of the lexical errors investigated in this study. The errors were attributed to the inconsistency of the English spelling system and overgeneralization or ignorance of spelling rules. 
- Students' writing is characterized by a variety of inflection uses in terms of wrong uses of nouns, verbs, adjectives or adverb. Inflection errors constituted (24.2\%) of the lexical errors investigated in this study.

The study showed collocation errors which constituted (14.3\%). Also, Foreign learners assume that for every word in their mother tongue, there is a single translation equivalent in the target language ( $T L)$. The errors under this category show an occurrence of $(17.4 \%)$, they are attributed to the fact that students formulated their ideas in their native language then translate into the target language and the result is the occurrence of erroneous sentences because some words cannot be translated and some language items do not have structural equivalents in the IL. The gap between the students' mother tongue proficiency and the English language standard is very big.

Synonyms Errors; this category shows an occurrence of (.5\%). Some synonyms share the same components of meaning; the result is often an appropriate usage. Phrasal Verbs; errors under this category show an occurrence of (.6\%) and they are because there is no item in Arabic comparable to phrasal verbs in English. Finally, the investigation showed that the students have considerable weakness in English Lexis, evident from their high percentage of errors investigated in this study. The study results are supposed to have clear pedagogical implications and applications, particularly in the areas of curriculum and teaching methodology.

\section{Conclusion}

The study's main objectives are to investigate, identify, and analyze the lexical errors committed by the EFL Learners at the Department of English language in Kassala University. The study's findings reveal that most learners face difficulties and commit errors when using the appropriate word to convey their thoughts and information, resulting from mother tongue interference and other factors such as over-generalization and incomplete application of rules of the target language. The results of the study reveal that the spelling errors constituted ( $32.5 \%$ ), wrong uses of inflections constituted (24.2\% ), collocation errors constituted (14\%), transfer errors constituted ( $17.4 \%)$, Synonym errors (.5\%), and phrasal verbs constituted (.6\%). The results of the Study are supposed to have clear pedagogical implications and applications, particularly in the area of curriculum and teaching methodology. The study is useful to EFL Learners to increase their awareness of English words, and useful for English language teachers, they can help improving students words knowledge through instructions and encouragement to use their particular techniques in finding the meaning of the new words. The results of this study can also be useful for course designers in a variety of ways. Evidence in the literature suggests that vocabulary measures, particularly lexical errors, are indicators of writing quality.

The area of lexical errors still needs more studies and investigation because it is a very wide and difficult one. Therefore, the area of lexical error need continues concentrated research. Similar studies can be conducted to investigate lexical errors in different areas. The lexical errors still need more studies and investigation because it is a very wide area and very difficult one. Therefore lexical errors needed continuous concentrated research. Although this research is concerned with lexical errors of EFL students, its results can be useful for teachers, course designers, and learners. Students, of course, have a great share in the dilemma. They need to increase their awareness of English words. They cannot always wait for teachers to make them competent writers. After all, the student will be blamed for this inability to use English words productively despite other academic inconveniences that also contribute to the problem.

In addition, teachers can help improve students' words knowledge through instruction and encouragement to use their particular techniques in finding the meaning of new words or drawing learners' attention to using dictionary (either monolingual or bilingual dictionaries) like the Oxford Advanced learner's Dictionary. The results of this research can also be useful for course designers in a variety of ways: department class hours allotted to teaching English language skills are limited compared to those allotted to courses of linguistics and literature. So, more class hours are needed to teach the student the necessary skills, especially English, for communicative purposes. The teaching and learning of spelling should be stressed in the course books before the university by giving spelling rules and patterns as far as possible. 


\section{References}

[1] AbiSamra, N. (2003). An analysis of errors in Arabic speakers' English writings. Investigating writing problems among Palestinian students studying English as a foreign language. Unpublished doctoral dissertation, P5.

[2] Ahmed, M. O. (1994). Acquisition of English lexis: a Study of Habits and Tactics. Khartoum University Press.

[3] Akande, A. T., Adedeji, E. O., \& Okanlawon, B. O. (2006). Lexical errors in the English of technical college students in Osun State of Nigeria. Nordic Journal of African Studies, 15(1), 71-89

[4] Bahns, J. (1993). Lexical collocations: A contrastive view. ELT journal, 47(1), 56-63.

[5] Hahn. (1987). Trial and Error" In English Teaching Forum Washington, 25(3)

[6] Hamad, A. (1995). Lexical Errors in Second Year English students of the faculty of Arts, University of Khartoum.

[7] Hatch, E. (1978). Second Language Acquisition. Newbury House

[8] Hemchua, S. \& Schmitt, N. (2006). An analysis of lexical errors in the English compositions of Thai learners. Prospect, 21, 3-25.

[9] James, C. (1998). Errors in language learning and use: Exploring error analysis. New

[10] York: Longman.

[11] Larsen-Freeman, D. (2012). From Unity to Diversity: Twenty-Five Years of Language-Teaching Methodology. In English teaching forum (Vol. 50, No. 2, pp. 28-38). US Department of State. Bureau of Educational and Cultural Affairs, Office of English Language Programs, SA-5, 2200 C Street NW 4th Floor, Washington, DC 20037.

[12] Leech, G. (1974). Semantics. Penguin Books Ltd, England

[13] Llach. M. P. (2007). Lexical errors in young EFL learners: How do they relate to proficiency measures? Interlinguistica, 17, 63-73.

[14] Lyons, J. (1977). Semantics: Volume 1.

[15] Mahmoud, A. (2005). Collocation errors made by Arab learners of English. Asian EFL journal, 5(2), 117-126.

[16] McCarthy, M. (1990). Vocabulary. Oxford: Oxford University Press.

[17] Meara, P. (1984). The study of lexis in interlanguage. In A. Davies, C. Criper \& Howatt (Eds.), Interlanguage. Edinburgh: Edinburgh University Press.

[18] Naba'h, A. A. (2011). Lexical Errors Made by In-Service English Language Teachers in Jordan. Damascus University Journal, $27(1), 2$.

[19] Shalaby, N. A., Yahya, N., \& El-Komi, M. (2009). Analysis of lexical errors in Saudi college students' compositions. Journal of the Saudi Association of Languages and Translation, 2(3), 65-92.

[20] Nasr, R. T. (1963). The teaching of English to Arab students. Longmans.

[21] Nation, I. S. P. (2001). Learning vocabulary in another language. Cambridge: Cambridge University Press.

[22] Nemser, W. (1974). Approximative Systems of Foreign Language Learners' In Richards JC (ed.) Error Analysis.

[23] Palmer, F. R. (1976). Semantics. A New Outline. Cambridge Univ.

[24] Sullivan, J. H. (2001). The challenge of foreign language teacher preparation: Addressing state teacher standards. The Clearing House, 74(6), 305-307.

[25] Sinclair, J. (1987). English Grammar. William Collins sons

[26] Szymanka, L. (2002). Lexical problems areas in the advanced learner corpus of written data. In Second Language Vocabulary Colloquium. Leiden University.

[27] Wang, L. (2003). Switching to first language among writers with differing second-language proficiency. Journal of Second Language Writing, 12(4), 347-375.

[28] Wardhaugh, R. (1970). The contrastive analysis hypothesis. TESOL quarterly, 123-130.

[29] Woodall, B. R. (2002). Language-switching: Using the first language while writing in a second language. Journal of Second Language Writing, 11(1), 7-28.

[30] Yule, G. (1985). The Study of Language. C. U. P. England 